\title{
Determinants of Fertility in Albania
}

\author{
Ines Nurja \\ University of New York Tirana, Albania
}

Ogerta Elezaj

Tirana University, Faculty of Economy, Albania

Doi:10.5901/ajis.2016.v5n3p129

\section{Abstract}

One of the major demographic changes during the last decade is the declining of fertility below the level necessary for the replacement of generations which identifies the end of the first demographic transition in the Albanian society. Albania recognizes a rapid and later demographic transition, which is characteristic of developing countries. While we know a lot about the timing of the fertility transition in different regions, we know much less about specific features in different periods. The aim of this paper is to use longitudinal micro-level data for Albanian population to study the relationship between socioeconomic status and fertility. Using the 2012 Albanian Living Standard and Measurement Survey (ALSMS) we analyze fertility behaviour. The results from survival analysis techniques suggest that the reduction of fertility goes in line with economic, social and cultural life of couples and families. In the models proposed in this paper fertility is measured by the number of children ever born for a woman. This variable is easily measurable. A stratified sampling technique was used to collect data from LSMS survey. Regression analysis was used to estimate the relationship between number of children and social-economic variables confirming the findings in other similar studies.

Keywords: fertility, socio-economic development, regression of Poisson.

\section{Introduction}

Albania has experienced a rapid decline in fertility. Starting from 1960 the number of children born to a woman of childbearing age almost halved every 30 years, and specifically from 6.8 children in 1960 to 3.1 children in 1990 and 1.6 children in 2014 [1]. Despite national policy pursued by the state until 1990, as the prohibition of abortion and the use of modern means of contraception, fertility is continuously reduced [2].

Albania's experience has shown that fertility can be reduced without the use of modern contraceptive methods, but is very influenced by economic and social developments. Despite the decline of fertility in general, there are still differences between the groups with different level of education and different economic status. Fertility is higher among women in rural areas, among women with lower education and those with inferior economic status. But will fertility rate decline in the future, at least to these categories of women?

It is not clear whether fertility will continue to decrease or there will be a reversal of fertility in the future. Researchers of 2011-2031 population projections [1] have formulated hypothesis of fertility decline, but also an increase in fertility rate. In this context, it is of a great interest to find the factors that affect fertility, to orient and coordinate development policies in the future.

At the beginning of 2000 (INSTAT, 2014) fertility in Albania was significantly below the level necessary for the replacement of generations. Economic, social and cultural developments in various stages are associated with different demographic events.

The total fertility rate (TFR) is a more direct measure of the level of fertility. The total fertility rate (TFR) can be interpreted as the number of children a woman would have during her lifetime if she were to experience the fertility rates of the period at each age. [3].This indicator shows the potential for population change in the country

A rate of 2.1 children per woman is considered the replacement rate for a population, resulting in relative stability in terms of total numbers. Rates of fertility above two children indicate populations growing in size and whose median age is declining. Rates below two children indicate populations decreasing in size and growing older. Total fertility rates are lower in - industrialized countries, especially Western Europe. Much attention has been paid to the status of women as an important determinant of fertility in developing countries, with emphasis on the importance of employment and education 
as measures to 'empower' them in society. The status of women and the strengthening of its role have progressed. Education and labor force participation of women are improved, but problems are evident by social groups and regions of the country. This paper will focus on these factors. The number of children ever-born reported by women can be used to study fertility - in Albania, as the dependent variable in a multiple regression and a set of characteristics of the mother as explanatory variables.

\section{Review of Literature}

Many authors explain the decline in fertility associated with social and economic developments, which motivate individuals, couples and families to reduce fertility $[4,5,6]$. The process of modernization, such as the development of education, urbanization, the expansion of non-agricultural sector has an impact in reducing fertility.

Enough experience confirm that fertility times ago was controlled by women more educated and with higher socialeconomic status $[7,8,9]$ and its decline later was the answer to the control of fertility in women less educated, with lower economic status, and in rural areas. The higher the educational level of women is, the stronger is the effect of education in the age of marriage and in fertility [10]. Also, other elements such as uncertainty of continuous employment, family responsibilities, lack of appropriate policies to support children's education, the ideology of "quality" in child rearing, financial costs of raising children, the difficulties of urban environment also seems to play a role in reducing fertility [11].

Other authors believe that the reduction of fertility in different stages, not necessarily is determined by socioeconomic factors such as levels of female education, employment, or urbanization [12, 13]; they consider behaviour factors, biological and cultural ones closest determinants that directly affect fertility; all other factors such as social, economic and environmental ones has an impact on fertility through these variables. Behavioural variables [14] areconsidered: the proportion of married women, the prevalence of contraceptive usage, abortion and the use of inhibitory effect of breastfeeding on fertility.

In literature in the recent decades, in the majority of developing countries, it is confirmed the decline in fertility in the group of less educated women achieved mainly due to a successful program of family planning [15]. Population development programs undoubtedly have contributed to the decline in fertility [11].

In Albania, the strongest decline of fertility belongs to the rural area. Total fertility rate in rural areas in 2008 was 1.8 children from 1.6 for Albania $[16,11]$. Total fertility rate was higher in rural areas, in mothers with less education level and lower economic status. The median age at first marriage is higher in urban areas, in urban Tirana (the capital), among women with higher education and higher wealth index.

Based on descriptive statistics, the use of family planning methods is positively related with women's education, economic status, area and region; women with higher education, those in urban areas, women in Tirana and with better economic level using more family planning methods; but when all the variables included in the multivariate regression model, education and economic status (wealth index) lose their explanatory power; with significant impact in the usage of any method of family planning are woman's age, number of children, gender preference, areas and access to information [17].

Albania's experience shows that in addition to social and economic development in the fertility decline, the promotion of family planning programs since 1990 has accelerated the process of its decline.

\section{Data and Methods}

\subsection{Data Source}

In our analyses we have selected from Albania Living Standard Measurement Survey (LSMS) conducted in 2012 the entire household where there was a woman with age between 15 to 49 having at least one child ever born [18]. In total we analyse 2778 household. LSMS is a multi-purpose survey conducted near households and one of the main sources of information to measure living conditions, the situation of poverty and to ensure a necessary tool to help policy makers in monitoring and developing social programs.LSMS was conducted in the context of continuing monitoring of poverty and the creation of a policy evaluation system in the framework of the National Strategy for Economic and Social Development (NSESD), now days National Strategy for Development and Integration (NSDI). The survey includes a sample of 6,671 households that constitute the survey units.

The variables used are age of women, education of women and spouse, employment of father, real consumption per capita and urban/rural area. Statistical package for social science (SPSS) was used for all the analysis. Simple 
correlation was used to find the association between the variables. Poisson regression was estimated wherever significant relations were observed.

\subsection{Measurement of Variables}

The dependent variable is the number of children ever born to women of childbearing age and explanatory variables were considered: real consumption per capita, age, woman education, father employment status and urban/rural.

Some authors have shown that the relationship between economic and fertility to the nearest variables is similar when economic status is measured as consumption per capita [19].

Real consumption per capita is a measure of the economic status of the family where the woman belongs to; it is calculated according to quartiles, where the fourth quartile (The highest level) is the reference category in this analyzes.

Next factor to measure the economic situation in the family is considered father employment status, a characteristic not just of one week before the interview, but likely to be sustainable.

Age is another explanatory variable on fertility where the age effects typically follow a parabolic upside distribution. The specific birth coefficients are low at younger ages, reaches its peak between 20-30 years old and then fall down at the end of reproductive period. Recognizing the nonlinear effect of age over fertility, in the model it is used also the age squared variable.

Women education is categorized into three levels low, medium and high. In the category of low education are included all the women with no education at all or their highest diploma attended is "Primary-4 years", in the medium education are included all the women where their highest diploma attended is "High School", and high education have been considered women who have a "University" diploma or post graduate studies.

Rural/ Urban explanatory is another explanatory variable on fertility. Despite the continued decline in fertility rates in rural and urban areas, in Albania historically the number of births in rural area is higher; differences between areas have become increasingly smaller, which results from an accelerated decline in fertility in rural areas.

\section{Results}

In LSMS survey 2012 the number of children ever born by women of childbearing age is calculated 2.3 children varying from 1 in 7 children. Number of children ever born is higher among mothers with lower education level, in families with lower consumption level, in rural area and the children's father status is unemployed (Appendix 1). LSMS 2012 is not designed to measure the number of children born but the results go in the same direction as those of the Albanian and Demographical Health Survey (ADHS) 2008-09. The lowest number of children belongs to women with high education level and higher consumption level (Figure 1)

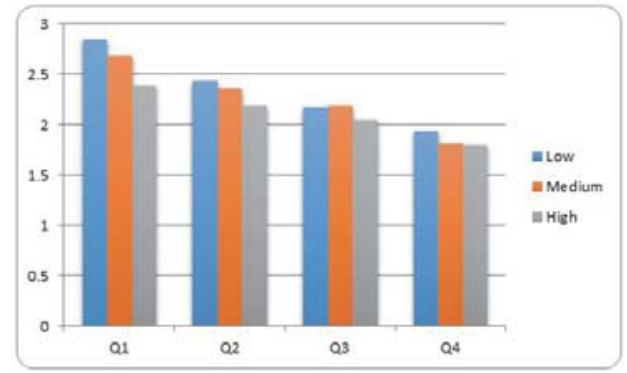

Figure 1: Number of children ever born by the real consumption quartiles and the women educational level

The differences in the average number of children ever born are significant between women's educational levels and by every quartile of real consumption per capita (Appendix 2).

Descriptive statistics are a good support of the analytical study, but the variables must also be addressed in addiction and their interconnections, as different phenomena are explained under the influence of several factors. Analytical data processing was done by means of Poisson's regression. Poisson regression is used when the dependent variable is number children ever born. Poisson regression is similar to the logistic model and is adopted when the 
dependent variable takes on only non-negative numbers and is more appropriate than ordinary least squares given that the average in a Poisson distribution is positive and the distribution of the number of children is non-normal. It is a special case of linear models, where the distribution of the dependent variable obeys the Poisson law and the relationship function is logarithmic. The Poisson regression model gives the logarithm of the odds ratio like a linear function of a set of explanatory variables. [20.

Four different Poisson regressions (Table 1) are conducted using individual data of the Living Standards Survey (LSMS 2012). All four variants are convenient and sustainable to explain the relationship among variables (summary tests (omnibus test) for the likelihood ratio chi-square were significant $(p<0.001)$.

The first variant $A$, explains the relationship between the number of children born and the economic status of woman family. The likelihood ratio shows that the number of children born is higher at lower levels of consumption per capita and the four quartile of consumption are important explanatory. Women with lower economic status (first quartile) have a number of children ever born $50 \%$ higher $(O R=1.501)$ than women belonging to the highest level (fourth quartile). The likelihood ratio is declining just as the number of children ever born from lowest consumer quartile to the highest is getting smaller.

In the version B two more variables are included, age and age squared to control biological fertility variations by age. In this specification model two variables are good explanatory factor of fertility.

Unlike version B, in the third version (C) level of education of women variable is added in the model. In this model low education level of women explains the significant impact of this variable on the number of children born, different from descriptive statistics which show significant differences in the number of children by the education of women, women with secondary and higher variant $\mathrm{C}$ no significant differences between the number of children, when other variables remain constant in the model. This variant highlights the decline of differences in the number of children born between women with secondary education level and high education level.

Table 1. The odds ratio (OR) of the explanatory variables on the number of children ever born - Poisson Regression

\begin{tabular}{|c|c|c|c|c|}
\hline \multirow{2}{*}{ Variables } & \multicolumn{4}{|c|}{ Odds ratio (OR) } \\
\hline & A & B & C & D \\
\hline \multicolumn{5}{|l|}{ Consumption Quartiles } \\
\hline First Quartile (lowest) & $1.501^{\text {tht }}$ & $1.489^{* k+k}$ & $1.460^{\text {*k+ }}$ & $1.473^{\text {tht }}$ \\
\hline Second Quartile & $1.289^{\text {t*t }}$ & $1.284^{\text {*kt }}$ & $1.266^{\text {*th }}$ & $1.274^{*+k x}$ \\
\hline Third Quartile & $1.165^{\text {tot }}$ & $1.168^{\text {**k }}$ & $1.156^{* t+k}$ & $1.161^{\text {t*k }}$ \\
\hline Fourth Quartile (RC) & 1 & 1 & 1 & 1 \\
\hline \multicolumn{5}{|l|}{ Age } \\
\hline Age & & $1.163^{\text {t*t }}$ & $1.164^{*+k}$ & $1.166^{\text {thk }}$ \\
\hline Age Square & & $.998^{* * *}$ & $.998^{k * k}$ & $.998^{k+k}$ \\
\hline \multicolumn{5}{|l|}{ Mother education } \\
\hline Low & & & $1.083^{*}$ & 1.037 \\
\hline Medium & & & 1.044 & 1.025 \\
\hline High (RC) & & & 1 & 1 \\
\hline \multicolumn{5}{|l|}{ Father Employment } \\
\hline Unemployed (RC) & & & & .982 \\
\hline Employed & & & & 1 \\
\hline \multicolumn{5}{|l|}{ Area } \\
\hline Rural & & & & $1.101^{\text {tht }}$ \\
\hline Urban (RC) & & & & 1 \\
\hline Constant & $1.855^{\text {tkt }}$ & $.095^{\text {tht }}$ & $.090^{\star * k}$ & $.086^{\star \star * t}$ \\
\hline
\end{tabular}

In the last version, D have been added two more variables, spouse employment status and woman residential area. Including all possible variables explains the economic and social development of fertility. Education of women loses explanatory power when other variables are kept constant in the model. With the exception of women's education and employment of the father, the other variables are statistically significant $(p<0.001)$. In rural areas the number of children ever born in 2012 was 10\% higher than in urban areas (OR = 1.10).

Number of children ever born is higher among women with the lowest living standard. Higher education is 
associated with an increased living standard. Analysis of the LSMS data confirms the conclusions reached in previous studies on the role of social and economic developments in Albania on fertility [2, 21,22, 23].

\section{Conclusions}

This study explores the relationship between fertility and socio-economic and cultural developments. The study of determinant factors is needed to explain the change in behavior of fertility between different population groups.

LSMS 2012 data are analyzed with descriptive and multivariate statistical techniques.Although descriptive statistics highlight the difference in the number of children ever born by consumption level, area of residence, mother education and father employment, multivariate analysis highlights the significant impact of the economic situation of the family where the woman belongs to, age, and area of living, while impact of education is less important. At this stage of progress, this demographic response emphasizes the role of economic development on fertility.At this stage of country progress, this demographic situation emphasizes the role of economic development on fertility.

Women with lower economic status (first quartile) have a number of children ever born $50 \%$ higher $(\mathrm{OR}=1,501)$ than women belonging to the highest level (fourth quartile). Number of children even born is higher in rural area compared to urban area

The improvement of the economic situation will be able to affect other demographic changes. It can be assumed that reproductive behaviour of women with a higher economic level will have an impact to women with lower levels of consumption.

The effects of social economic factors on fertility suggest policy guidelines that promote their impact on quality of life in the family and in raising children, especially in rural areas.

\section{References}

Instat, ShqipëriProjeksionet e Popullsisë 2011-2031Tiranë: ShtypshkronjaGent.Grafik, Maj 2014, p.19

Dumani, B. (1995)Natalitéetdeveloppment socio-economique en Albanie, Cahier du Cidep28,Academia Bruylant, L'Harmatan, p.20-27

Vidal-Zeballos D. (1994) Social strata and its influence on the determinants of reproductivebehaviour in Bolivia", Demographic and Health Surveys Comparative studies No. 13. Maryland: Macro International, USA.

Bongaarts J, Watkins SC. (1996) Social interaction and contemporary fertility transitions. Population and Development Review 22(4): $650-671$.

DumaniB, Subashi B. (2011) Determinants of fertility in Albania with particular attention to the role of emigration,Advanced analysis of the Albania DemogrAphic and Health survey 2008-09 data, Instat, Pegi, p. 120-145

Falkingham, J. Gjonça A. 2001. Fertility Transition in Communist Albania, 1950-90, in Population Studies, 55 (3), pp. 309-318.

McNay K. (2003) Why are uneducated women in India using contraception? A Multilevel Analysis. Population Studies 57(1): 21 [PubMed]

Arokiasamy P (2009) Fertility decline in India: Contributions by uneducated women using contraception.Economic and Political Weekly 44 (30): 56-60.

Freedman R (1995) Asia's Recent Fertility Decline and Prospects for Future Demographic Change Asia-Pacific Population Report. Honolulu: East-West Center, Program on Population.

Maitra P.(2001) Age at marriage and total fertility in Nepal Discussion Papers, ISSN 1441-5429, Department of Economics, Monash University, Australia.

http://wwww.www, NabanitaMajumder and Faujdar Ram,Explaining the Role of Proximate Determinants on Fertility Decline among Poor and Non-Poor in Asian

Countries, Hemachandra Reddy, Academic Editor, PLoS One. 2015; 10(2): e0115441. Published online 2015 Feb 17.10.1371journal.pone.0115441

Bongaarts J (2002) The end of the fertility transition in the developing world. Completing the Fertility TransitionDepartment of Economic and Social Affairs,

Population Division, ESA/P/WP.172/Rev.1. New York: United Nations, pp. 290-305. Forthcoming in Population Bulletin of the United Nations.

Bongaarts J, Watkins SC (1996) Social interaction and contemporary fertility transitions. Population and Development Review 22(4): 645-666

Bongaarts J, Potter RG (1983) Fertility, biology and behavior. An analysis of the Proximate Determinants. New York: Academic Press.[15] Bhat PNM (2002) Returning a favour: Reciprocity between female education and fertility. World Development30 (10): 1795-1801.

Bhat PNM (2002) Returning a favour: Reciprocity between female education and fertility. World Development30 (10): 1791-1803.

Instat, Institute of Public Health, Albania, ICF Macro, Calverton, Maryland, USA, March 2010 Demographic and health survey, p. 53, 56, 91 
Ismaili F, XinxoS.BiciR (2014)Factors affecting family planning behavior in Albania, Advanced analysis of the Albania DemogrAphic and Health survey 2008-09 data, Instat, Pegi,p 113

LSMS database: http://www.instat.gov.al/en/figures/micro-data.aspx

Bollen KA, Glanville JL, Stecklov G (2002) Economic status proxies in studies of fertility in developing countries: Does the measure matter? Population Studies 56(1): 81-96.doi: 10.1080/00324720213796 [PubMed]

David P, Lindstrom S, Giorguli S. (2007) The interrelations between fertility, family maintenance and Mexico-U.S. migration. Demogrphic research, volume 17, article 28, pp 821-858

Gjonca A, Aassve A, Mencarini L.2008. Albania: Trends and patterns, proximate determinants and policies of fertility change. Demographic research 19, no. 11: pp 261-292

Lerch M.2013. Patriarchy and fertility in Albania volume 29, article 6, pages 133-166

Nurja I, SevraniK,DumaniB. 2014. Education and povertyin Albania based on Living Standards Measurements Survey (LSMS), International Journal of Science, Innovation and Technology. Tiranë, 2014,pp 49-59.

\section{Appendix}

Appendix 1. Descriptive statistics, LSMS 2012

\begin{tabular}{|l|c|}
\hline Variables & The average number of children ever born \\
\hline Real Consumption per Capita & 2.78 \\
First Quartile (lowest) & 2.39 \\
Second Quartile & 2.16 \\
Third Quartile & 1.86 \\
\hline Fourth Quartile (highest) & \\
\hline Mother education & 2.41 \\
Low & 2.23 \\
Medium & 1.98 \\
High & \\
\hline Father Employment & 2.37 \\
\hline Unemployed & 2.26 \\
Employed & \\
\hline Area & 2.43 \\
\hline Rural & 2.17 \\
\hline Urban & 2.30 \\
\hline Total & \\
\hline
\end{tabular}

Appendix 2. Differences of average number of children by consumption and mother education level 2012

\begin{tabular}{|c|c|c|c|c|}
\hline \multirow{2}{*}{ (I) Percentile Group of real consumption } & \multirow{2}{*}{ (J) Percentile Group of real consumption } & Sig. Mean Difference (I-J) & \multicolumn{2}{|c|}{ 95\% Confidence Interval } \\
\cline { 3 - 5 } & 2 & & Lower Bound & Upper Bound \\
\hline 1 & 2 & .000 & .2691 & .5182 \\
\hline & 4 & .000 & .4985 & .7476 \\
\hline 2 & 3 & .000 & .8046 & 1.0538 \\
\hline & 4 & .000 & .1050 & .3539 \\
\hline 3 & 4 & .000 & .4110 & .6601 \\
\hline (I)mother education & (J)mother education & .000 & .1816 & .4306 \\
\hline 1.00 & 2.00 & & & .0866 \\
\hline & 3.00 & .000 & .3021 & .5700 \\
\hline 2 & 3.00 & .000 & .1152 & .3975 \\
\hline
\end{tabular}

